\title{
First-Line Therapy
}

National Cancer Institute

\section{Source}

National Cancer Institute. First-Line Therapy. NCI Thesaurus. Code C45792.

The preferred standard treatment for a particular condition. 